\title{
Fertility preservation in gynaecologic malignancy: imaging role in treatment planning
}

\author{
I Papadopoulou, M Qureshi, N Butterfield, N Bharwani, A Rockall ${ }^{*}$ \\ From International Cancer Imaging Society Meeting and 15th Annual Teaching Course (ICIS 2015) \\ London, UK. 5-7 October 2015
}

\section{Learning objectives}

To know the options for fertility preservation in women with cervix, ovarian or endometrial cancer.

To understand the role and limitations of imaging in selection of patients for fertility preserving options.

To recognise the appearances of early stage disease that fulfil the criteria for eligibility for fertility preservation.

\section{Content organisation}

A significant number of women with gynaecological cancer are of childbearing age and have not completed their families. In these younger women, consideration of fertility-sparing options is very important. This poster will describe the fertility-sparing treatment options that are currently available and delineate the role of imaging in the selection of suitable patients. A review of the current literature will be presented to provide an evidence base. In cervix cancer, MRI is used to delineate the size, position and stage of the tumour for the selection of patients suitable for radical trachelectomy. In complex adnexal masses, MRI with diffusion and perfusion is used to categorise the likelihood of invasive or borderline malignancy in order to allow potential fertility preservation where possible. In endometrial cancer, MRI is used to rule out imaging signs of invasive disease prior to consideration of hormonal treatment. Imaging is also used in patient follow-up for the detection of recurrent disease. Each of these scenarios will be illustrated.

\section{Conclusion}

Imaging plays a major role in the management of patients who are considering fertility-preserving treatment options for gynaecologic malignancy.

\footnotetext{
* Correspondence: a.rockall@imperial.ac.uk

Imperial College London, Exhibition Road, London, SW7 2AZ, UK
Published: 2 October 2015

doi:10.1186/1470-7330-15-S1-P35

Cite this article as: Papadopoulou et al:: Fertility preservation in gynaecologic malignancy: imaging role in treatment planning. Cancer Imaging 2015 15(Suppl 1):P35.
Submit your next manuscript to BioMed Central and take full advantage of:

- Convenient online submission

- Thorough peer review

- No space constraints or color figure charges

- Immediate publication on acceptance

- Inclusion in PubMed, CAS, Scopus and Google Scholar

- Research which is freely available for redistribution
( Biomed Central 